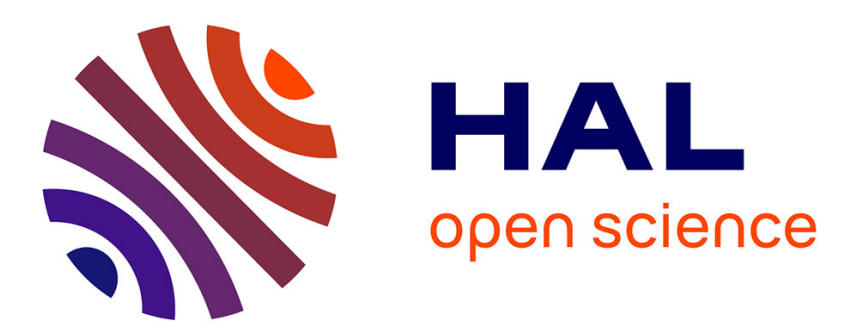

\title{
Dynamic micro-fracture of metals under shock loading by electric gun
}

\author{
S. Chengwei, F. Shuping, L. Xinping, Y. Xi, H. Zhuping
}

\section{To cite this version:}

S. Chengwei, F. Shuping, L. Xinping, Y. Xi, H. Zhuping. Dynamic micro-fracture of metals under shock loading by electric gun. Journal de Physique IV Proceedings, 1994, 04 (C8), pp.C8-355-C8-360. 10.1051/jp4:1994854 . jpa-00253414

\section{HAL Id: jpa-00253414 https://hal.science/jpa-00253414}

Submitted on 1 Jan 1994

HAL is a multi-disciplinary open access archive for the deposit and dissemination of scientific research documents, whether they are published or not. The documents may come from teaching and research institutions in France or abroad, or from public or private research centers.
L'archive ouverte pluridisciplinaire HAL, est destinée au dépôt et à la diffusion de documents scientifiques de niveau recherche, publiés ou non, émanant des établissements d'enseignement et de recherche français ou étrangers, des laboratoires publics ou privés. 


\title{
Dynamic micro-fracture of metals under shock loading by electric gun
}

\author{
S. Chengwei, F. Shuping, L. Xinping, Y. Xi and H. Zhuping \\ Southwest Institute of Fluid Physics, P.O. Box 523, Chengdu, Sichuan 610003, China
}

\begin{abstract}
Resume - Des specimens d'aluminium, cuivre OFHC et alliage titane Ti-6Al-4V sont charges par un canon electrique de deux etages. Le procede de nucleation et croissance de micro-vides dans les specimens est decrit avec le model NAG, la relation constitutive et la simulation numerique. Il est predit que l'intensite de spallation d'aluminium pur monte avec le taux formatique volumique unchargeant plus que $6 \times 10^{4} \mathrm{~s}^{-1}$.
\end{abstract}

\begin{abstract}
Aluminum, OFHC copper and Ti-6Al-4V specimens have been impacted with the two stage electric gun. The process of nucleation and growth of micro voids in the specimens is well described by the NAG model and related constitutive relation and numerical simulation. It is predicted that the spall strength of pure aluminum goes up with the unloading bulk strain rate greater than $6 \times 10^{4} \mathrm{~s}^{-1}$.
\end{abstract}

\section{INTRODUCTION}

Dynamic fracture in shocked materials is a strain rate dependent process in which micro voids or other flaws occur. Sometimes they lead to damage through nucleation, growth, coalescence and interaction. Meanwhile the flaws affect the macro stress field in the material, so that the dynamic constitutive relation should take fracture effects as well as rate effects into account. The constitutive relation employed here is based on the Gurson's overstress model ${ }^{[1]}$, while the solid materials (matrixes) are represented by Perzyna's overstress model. Thus, a new yield function considering rate and micro-fracture effects and the related plastic stress-strain relation were obtained. In order to check this model, we have performed the experiments and numerical simulations described in this paper.

A new loading technique, using an electric gun to indirectly drive the secondary impactor, has been developed. It is called the two stage electric gun, but its heavier impactor has a lower velocity than that for the common one stage electric gun. It breaks the restriction that the electric gun can drive high speed $(\mathrm{km} / \mathrm{s})$ thin plastic flyers only, and provides low speed $\left(10^{2} \mathrm{~m} / \mathrm{s}\right)$ sub-millimeter thick metallic impactors for elastic-plastic dynamics and dynamic fracture experiments. It should be noted 
that this new promising technique is simple, effective and economical ${ }^{[2]}$.

Furthermore, we improved the 1D reactive hydrodynamic-elastic-plastic code $\mathrm{SSS}^{[\mathrm{G}}$ by incorporating the constitutive relation and the Seaman's NAG model ${ }^{[10]}$. Numerical simulations with the code SSS can predict the micro void distributions as well as the material response for metals under planar shock loading. The numerical simulations also reproduce the details of target's free surface velocity histories, especially the important velocity recession process. In contrast to it, the common spall criterion can provide the spall thickness and the target response before spallation only. The reason is that the criterion could be used only for objectively judging the spall process and does'nt interact with the calculated stress or strain field.

The strain rate dependence of a material's dynamic properties is an important aspect of its constitutive relation. Using the considered model it is predicted that the spall strength of pure aluminum will increase rapidly with the stain rate greater than $6 \times 10^{4} \mathrm{~s}^{-1}$, where the spall strength is defined as the local tensile stress when the void volume density first reaches 0.09 .

\section{EXPERIMENTS}

The electric gun works by means of an electrically exploding metallic foil. When a pulsed current passes through the bridge foil, a high pressure plasma drives a thin plastic flyer to hit the attenuator in the case of two stage electric gun (Fig.1). Because of its different impedance the impactor previously attached to the other surface of the attenuator can be driven to freely fly as soon as the reflective rarefaction reaches its rear interface with the attenuator. The experimental assembly is illustrated in Fig.1, and the main parameters and their adjustable ranges are as follows:

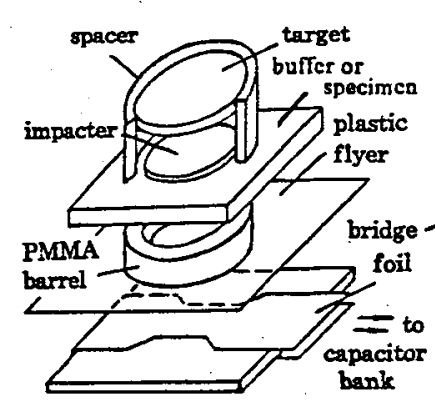

(a) electric gun

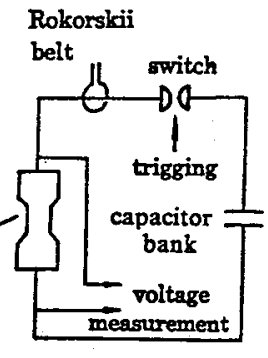

(b) circuit

capacitor bank $36 \mu \mathrm{F}$, charging voltage $10-15 \mathrm{kV}$, peak current $361 \mathrm{kA}$, circuit inductance $65 \mathrm{nH}$, Mylar flyer $\Phi 20 \times$ $0.2(\mathrm{~mm})$, velocity $2 \sim 6 \mathrm{~km} / \mathrm{s}$, glass epoxy attenuator $\Phi 70 \times 3 \sim 8(\mathrm{~mm})$, aluminum impactor $\Phi 15 \times 0.7(\mathrm{~mm})$, velocity $100 \sim 400 \mathrm{~m} / \mathrm{s}$, flatness of impact $\leqslant 30 \mathrm{~ns}$, shock wave in aluminum targets: velocity $5.42-5.62 \mathrm{~km} / \mathrm{s}$, pressure $0.73-3.03 \mathrm{GPa}$, pulse duration $2.6 \mu \mathrm{s}$.

Fig.1 Schematic of two stage electric gun

The experimental data for six shots in the aluminum tests are listed in Tab.1.

Table 1 Experimental Data of Aluminum

\begin{tabular}{c|c|c|c|c|c|c}
\hline Shot No & 1 & 2 & 3 & 4 & 5 & 6 \\
\hline Impact speed (m/s) & 144 & 267 & 330 & 714 & 761 & 787 \\
\hline Al impactor thickness (mm) & 0.7 & 0.7 & 0.7 & 2.0 & 2.0 & 2.0 \\
\hline Al target thickness (mm) & 2.0 & 3.0 & 3.0 & 6.0 & 6.0 & 6.0 \\
\hline
\end{tabular}


Shots 1-3 were performed with the two stage electric gun mentioned above and for the commercial pure aluminum (type L2). Shots 4-6 were done with explosive loading and for the aluminum alloy (type LY12) ${ }^{[3]}$.

\section{CONSTITUTIVE RELATION AND THE NAG MODEL}

Based on the Gurson's model an elastic-viscoplastic constitutive relation considering strain rate and micro fracture effects has been proposed ${ }^{[4]}$, where the Perzyna's model is employed for the matrix. A yield function then results from this new model,

$$
\left.\left(\sigma / Y_{0}\right)^{2} \operatorname{ch}[4 \sqrt{n /(1+5 f})\left(\dot{E}_{a} / \dot{\varepsilon}_{0}\right)^{n / s}\left(P / X_{0}\right)^{2}\right]+2 f \cdot \operatorname{ch}\left(3 q P / 2 Y_{0}\right)-1-f^{2}=0
$$

where $Y_{0}=\sigma_{0}\left[\left(\dot{E}_{a} / \dot{\varepsilon}_{0}\right)^{n}+1\right], \quad X_{0}=\left(2 \sigma_{0} / 3\right)\left[-\ln f+\left(2^{n / 2} / n\right)\left(\dot{E}_{a} / \dot{\varepsilon}_{0}\right)^{n}\left(f^{-n}-1\right)\right], \quad q=$ $-\left(2 Y_{0} / 3 X_{0}\right) \ln f, \quad \dot{E}_{a}{ }^{2}=(2 / 3) \dot{E}_{i j} \dot{E}_{i j}, \quad \sigma:$ the flow stress, $\sigma_{0}$ : yield strength of matrix material, $\dot{E}_{i j}$ : strain rate deviator, $\dot{S}_{i j}$ : stress deviator, P: the average stress, f: void volume fraction, $\dot{\varepsilon}_{0}$ and $\mathrm{n}(0<\mathrm{n}<1)$ are material constants. The dynamic fracture dependent constitutive relation can be writen as follows ${ }^{[1,4]}$

$$
\begin{gathered}
P / \sigma_{0}=\frac{1}{3}\left(\frac{\dot{E}_{a}}{\dot{\varepsilon}_{0}}\right)^{n}\left[\omega U_{n}+\frac{2-\omega^{2}}{n+1} \frac{\partial U_{n}}{\partial \omega}\right]+\frac{1}{3}\left[\omega U_{0}+\left(2-\omega^{2}\right) \frac{\partial U_{0}}{\partial \omega}\right] \\
\frac{\sum_{e}}{\sigma_{0}}=\left(1-\frac{\omega^{2}}{2}\right)^{1 / 2}\left(\frac{\dot{E}_{a}}{\dot{\varepsilon}_{0}}\right)^{n}\left[U_{n}-\frac{\omega}{n+1} \frac{\partial U_{n}}{\partial \omega}\right]+\left(1-\frac{\omega^{2}}{2}\right)^{1 / 2}\left[U_{0}-\omega \frac{\partial U_{0}}{\partial \omega}\right]
\end{gathered}
$$

$\omega=2 \dot{E}_{n n} / 3 \dot{E}_{a}, \quad \dot{E}_{n n}$ : macro bulk strain rate, $\sum_{e}=\left(3 \dot{S}_{i j} \dot{S}_{i j} / 2\right)^{1 / 2}$ : macro effective stress deviator, $U_{0}=U_{n} I_{n=0}$, and

$$
U_{n}=\frac{\omega}{2} \int_{0}^{\pi} \sin \theta d \theta \int_{\omega}^{\omega / f} x^{-2}\left[1-\frac{\omega^{2}}{2}-\frac{1}{2}\left(1-\frac{\omega^{2}}{2}\right)^{1 / 2}(1+3 \cos 2 \theta) x+x^{2}\right]^{(n+1) / 2} d x
$$

The nucleation and growth (NAG) model for micro voids and cracks was proposed by Seaman and other workers ${ }^{[5]}$. The evolution of nucleation is described by

$$
\begin{array}{ll}
\dot{N}= \begin{cases}\dot{N}_{0} \exp \left[\left(P-P_{n 0}\right) / P_{1}\right], & P \geqslant P_{n 0} \\
0, & P \leqslant P_{n 0}\end{cases} \\
N(R)=N_{0} \exp \left(-R / R_{0}\right)
\end{array}
$$

where $\dot{N}$ : nucleation rate, $\mathrm{N}_{0}$ : total void number per $\mathrm{cm}^{3}, \mathrm{~N}(\mathrm{R})$ : the cumulative void number per $\mathrm{cm}^{3}$ with radius larger than $\mathrm{R}, P_{1}$ : adjustable pressure for nucleation. The equation for void growth is

$$
\dot{R} / R=\left(P-P_{80}\right) / 4 \eta
$$

$\eta$ : material viscosity, $\dot{N}_{0}, R_{0}, P_{1}, P_{m 0}$, and $P_{s 0}$ are material constants, for aluminum L2 or LY12 here, $\quad \dot{N}_{0}=3 \sim 4 \times 10^{9} / \mathrm{cm}^{3} / \mathrm{sec}, \quad \mathrm{R}_{0}=1 \sim 3 \times 10^{-4} \mathrm{~cm}, \mathrm{P}_{1}=-2.5 \times 10^{8} \mathrm{dyne} / \mathrm{cm}^{2}$, $P_{n 0}=-0.2 \sim-1.0 \times 10^{9}$ dyne $/ \mathrm{cm}^{2}, \quad P_{g 0}=-1 \sim-3 \times 10^{9} \mathrm{dyne} / \mathrm{cm}^{2}$. In addition, the Mie-Gruneisen 
equation of state is used for solid and porous materials, also porosity (micro-fracture) dependent shear modulus and yield strength are incorporated into the code $\operatorname{SSS}^{\left[{ }^{6]}\right.}$, so that better numerical simulations could be performed. Considering the interaction of micro voids and the available experimental data, we set the critical condition for coalescence as $\mathbf{f}=\mathbf{0 . 0 9}$ for spallation.

\section{RESULTS AND DISCUSSION}

The micrographs of sectioned targets for Shots 1-3 are shown in Fig. 2 and indicate the process of nucleation, growth and coalescence of voids with impact speed increasing. Figs 3-4 show the void distributions for Shot 1 and 2, both the measured and calculated ones, where the peak position predicts the spall thickness in Shot 3.

In order to understand the target response to spallation, the free surface velocities were calculated for Shots 4-6, where the experimental data were measured with capacitor transducers. As shown in Tab.2 and Fig.5 for Shot 4-6 the detail of the velocity history is reproduced, especially the velocity recession that characterizes the unloading strain rate and the spall strength. Also the calculation with simple spall criterion (stress gradient and cumulative damage) is shown in Fig.5(b) from which it is concluded that they may provide the right response before spall and the spall thickness only.

Similarly the nucleation and growth of micro voids in OFHC copper and Ti-6Al-4V specimens have been observed (Fig.6, 7). It should be noted that the strain bands occur in the Ti-6A1-4V specimen loaded at lower strain rates and with explosive-driven thicker impactor ${ }^{[7]}$. The mechanism and condition for fracture feature transition from strain bands to micro voids are still unknown.
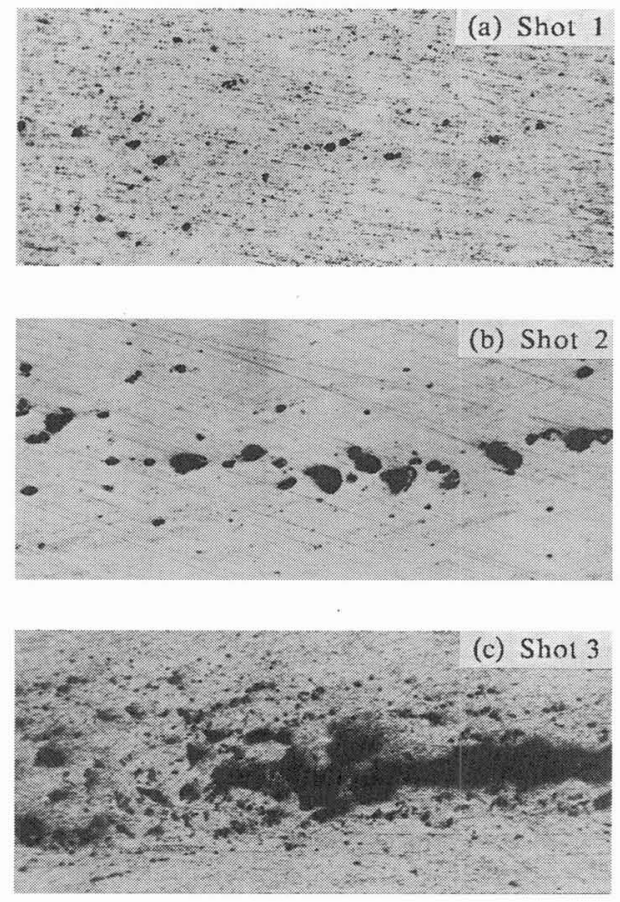

Fig.2 Micrographs of L2 aluminum target
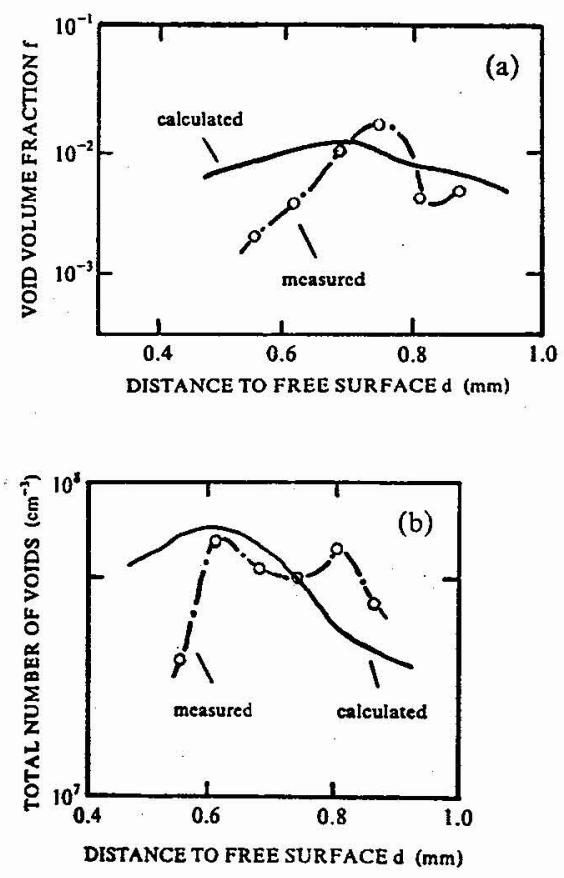

Fig.3 Void distributions for Shot 1 
Table.2 Measured spall strength of LY-12 aluminum alloy

\begin{tabular}{c|c|c|c|c|c}
\hline Shot No & $\begin{array}{c}\text { Impacter } \\
\text { velocity } \\
\mathbf{v}(\mathrm{km} / \mathrm{s})\end{array}$ & $\begin{array}{c}\text { Impact } \\
\text { pressure } \\
\mathrm{p}(\mathrm{GPa})\end{array}$ & $\begin{array}{c}\text { Strain rate } \\
\dot{\varepsilon}\left(10^{4} \mathrm{~s}^{-1}\right)\end{array}$ & $\begin{array}{c}\text { Free surface } \\
\text { velocity pullback } \\
\Delta \mathrm{u}_{\mathrm{f}}(\mathrm{km} / \mathrm{s})\end{array}$ & $\begin{array}{c}\text { Spall } \\
\text { strength } \\
\sigma_{\mathrm{g}}(\mathrm{GPa})\end{array}$ \\
\hline 4 & 0.714 & 5.75 & 1.00 & 0.14 & 1.09 \\
\hline 5 & 0.761 & 6.16 & 1.07 & 0.14 & 1.09 \\
\hline 6 & 0.787 & 6.39 & 1.19 & 0.17 & 1.20 \\
\hline
\end{tabular}

Finally the strain rate $\dot{\varepsilon}$ dependence of spall strength $\dot{\sigma}_{x}$ is explored by the numerical simulation, though the measurement of it is rather difficult. The spall strength shown in Fig.8 means the tensile stress as the local void volume fraction reaches 0.09 . The trend of $\sigma_{\mathrm{s}}$ vs $\dot{\varepsilon}$ is something like $\sigma_{s} \propto \dot{\varepsilon}^{1 / 3}$, just as predicted by fracture mechanics and stress wave models ${ }^{[7,8]}$, and observed in the laser driven shock wave loading experiments ${ }^{[7,9]}$. It is concluded that the model employed in this paper can describe the behavior of strain rate dependence besides the void distributions and the target response to shock loading.
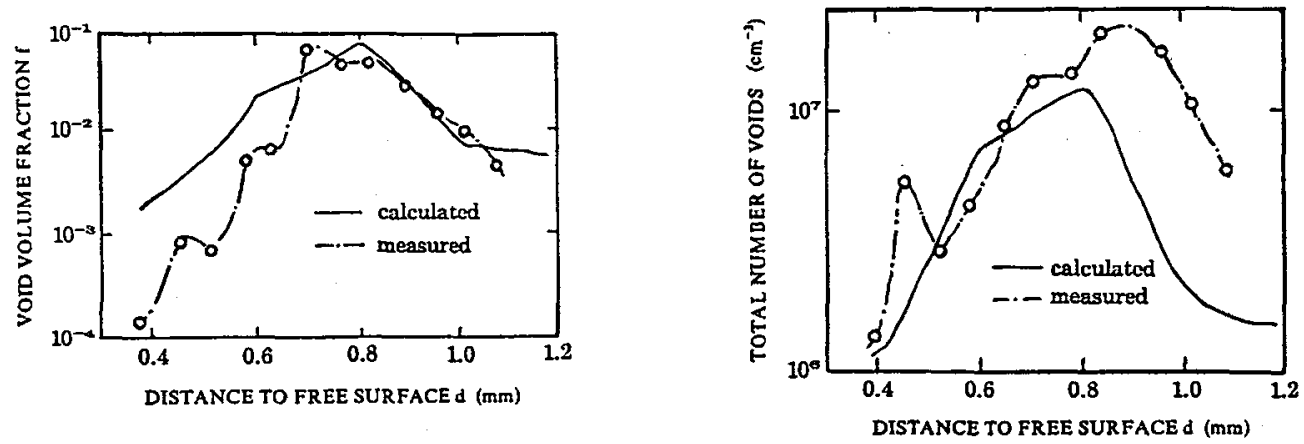

Fig.4 Void distributions for Shot 2
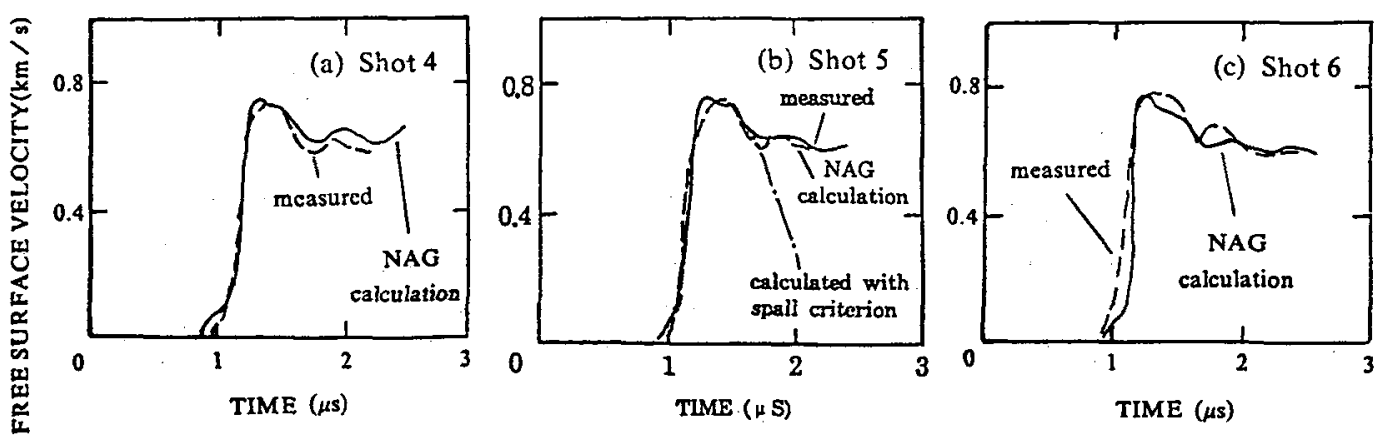

Fig. 5 Free surface velocity histories for Shot $4 \sim 6$ 

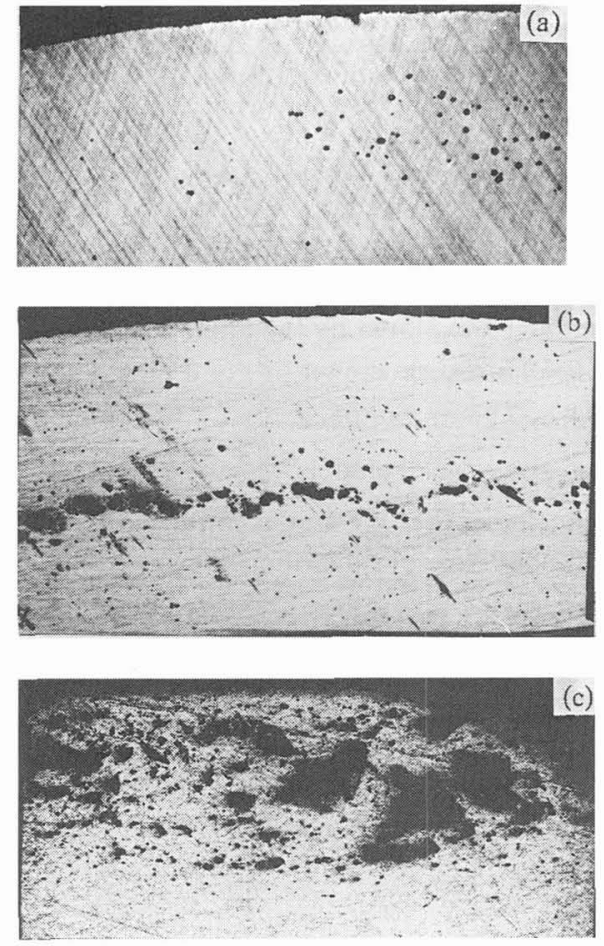

Fig. 6 Micrographs of OFHC copper target

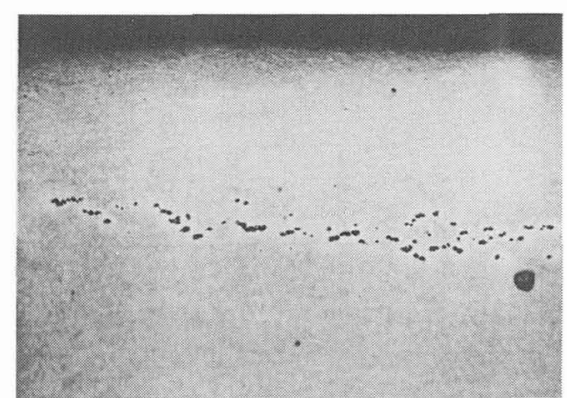

Fig.7 Micrograph of Ti-6Al-4V target

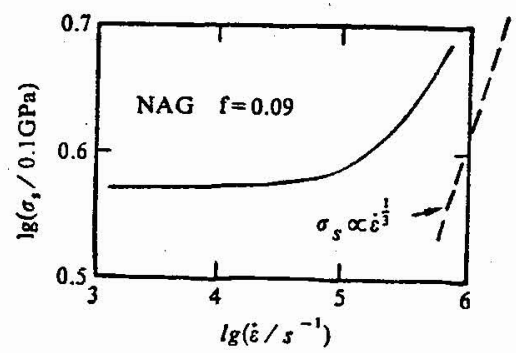

Fig. 8 Calculated strain rate, $\epsilon$, dependence of spall strength, $\sigma_{\mathrm{s}}$

\section{REFERENCES}

1. Gurson A.L., "Plastic Flow and Fracture Behavior of Ductile Materials Incorporating Void Nucleation, Growth and Interaction", Ph.D Thesis, Division of Engineering, Brown Univ., 1975

2. Zhang Z.Z., Feng S.P., et al., Chinese Journal of High Pressure Physics 5(2) (1991) 137.

3. Zhou G.Q., Li Y.C., J. de Physique Colloque C3 Suppl. Tome 49 (1988) 497.

4. Sun L.Z., "A Model for Dynamic Fracture of Ductile Materials", MA Thesis, Mechanics Department, Peking Univ., 1989

5. Barbee T.W., Seaman L., et al, J. Mater.7 (1972) 393.

6. Sun Chengwei, Chinese Journal of Computational Physics 3(2) (1986) 142.

7. Sun Chengwei, Zhuang Siming et al., "Dynamic Failure and Fracture in Metals at High Strain Rate", Proc. of Int. Symp. on Impact Mechanics, IUTAM, October 11-15, 1993, Beijing, China. (to be published)

8. Grady D.E., J. Mech. Phys. Solids 36(3) (1988) 353.

9. Eliezer S. and Gilath I., J. Appl. Phys. 67(2) (1990).715.

10. Curran D.R., Seaman L., Shockey D.A., Phys. Reports 147(5 6) (1987) 253. 